\title{
Climate Change Projections for Mediterranean Region with Focus over Alpine Region and Italy
}

\author{
Paola Faggian \\ Department of Sustainable Development and Energy Sources, Ricercasul Sistema Energetico-RSESpa, Milano 20134, Italy
}

\begin{abstract}
Climate change projections over the Mediterranean region have been elaborated by using the outputs of ten ENSEMBLES regional climate simulations with an horizontal resolution of $25 \mathrm{~km}$ under the SRES A1B emission scenario. The analysis concerns some surface atmospheric variables: mean sea level pressure, temperature, precipitation and wind speed. At first, model validations have been performed by comparing model results with E-OBS and ERA-Interim data in reproducing the last decades over some Italian sub-areas and the Alpine region. In spite of the considerable spread in the models' performances to represent the reference climate, a multi-model reconstruction has been computed and some seasonal climate change projections have been elaborated. About the mean climate changes, the more significant signals expected by 2050 are a maximum warming (about $2{ }^{\circ} \mathrm{C}$ ) and maximum drying (about 20\%) in the southern Europe in summer. Moreover, the results indicate an increasing risk for some severe weather conditions: more days of extremely high temperature in summer over the whole area, a greater occurrence of flooding and storms over coasts during spring and autumn seasons and a more serious wet-snow event over Alpine region in winter. No significant signals of wind changes have been detected.
\end{abstract}

Key words: ENSEMBLES simulations, Mediterranean climate change, future multi-model projections.

\section{Introduction}

Evidence for an unequivocal warming world comes from multiple climate indicators: independent long records of global average (land and ocean) show that the decade $2002-2011$ was $0.77-0.80{ }^{\circ} \mathrm{C}$ warmer than the pre-industrial average. In the same decade, the average increase temperature for Europe land area was $1.3{ }^{\circ} \mathrm{C}[1]$. Moreover, it is evident that it is increasing the number of people living in river basins under high water stress, as well as there is high confidence that water stress is increasing over southern Europe. Because of its complex morphology and socio-economic conditions, both gradual climate changes and extreme weather events represent severe risks for infrastructure vulnerability in the Mediterranean basin, with significant social and economic consequences. So, Mediterranean region has been identified as one of the most prominent "Hot-Spots" in the future climate projections [2]. This

Corresponding author: Paola Faggian, physicist, main research field: climatology. E-mail: paola.faggian@rse-web.it. area is characterized by a peculiar climate: mild and wet during the winter, hot and dry during the summer. Lying in a transition zone between the arid North Africa climate and the midlatitude variability of central and northern Europe, Mediterranean basin is affected by interactions between tropical processes and midlatitude synoptic activity driven by the westerly flow. These conditions allow that small variations of the general circulation, shifts of mid-latitude storm tracks or sub-tropical high pressure cells, can imply significant changes in the Mediterranean climate. Previous studies based on the analysis of CMIP3 general circulation models (GCMs) (among others [3, 4]), indicate a significant warming and summer precipitation decrease, despite global models are too coarse in their spatial resolution (typically 100-300 km) to properly represent the local climate processes induced by the complex Mediterranean basin orography. Thanks to worldwide efforts carried out by research groups, coordinated projects have been set up to generate and distribute 
large samples of high resolution simulations achieved by using Regional Climate Models (RCMs) nested in GCMs. Among different international initiatives, some European Projects are reminded here: PRUDENCE, CIRCE and ENSEMBLES [5-7]. The latter is a multi-model ensemble system providing regional projections over Europe at $25 \mathrm{~km}$ resolution and represents one of the major efforts to study the regional climate change over Europe.

In the framework of World Climate Research Program Coordinated Regional Downscaling Experiment CORDEX [8], the Med-CORDEX initiative has been proposed by the Mediterranean climate research community to provide new very high-resolution RCMs (up to $10 \mathrm{~km}$ ) to understand the processes responsible for Mediterranean climate variability and trends. Nowadays, only two simulations are available at the resolution of $0.11^{\circ}$ (about $12 \mathrm{~km}$ ) in Med-CORDEX database. The number of available independent numerical experiments is as important as the horizontal resolution to evaluate model uncertainties [9]. Since an horizontal resolution ranging from $50 \mathrm{~km}$ to $20 \mathrm{~km}$ should be sufficient to simulate realistic circulation over the Mediterranean basin $[10,11]$, in this work, ten transient ENSEMBLES simulations have been considered with an horizontal resolution of $25 \mathrm{~km}$ until the year 2050 .

The purpose of this work is neither to study all the simulation available in the ENSEMBLES database nor to provide an exhaustive assessment of the differences among the performance of RCMs driven by "perfect" boundary conditions [12]. Its goal is to issue a quantitative insight about probabilistic long-term fluctuations for the forthcoming decades, considering that the relative contribution of emission scenario to overall uncertainty is very small (below $10 \%$ [13]) in investigations until the mid of the $21 \mathrm{st}$ century.

The paper is structured as follows: the analysis domain, reference data and model simulations used in this study are described in section 2. The criteria adopted to evaluate the models' performances and the methodologies applied to elaborate future scenarios are depicted in section 3 . The results are discussed in section 4 by investigating both gradual changes and intense weather events because of their serious impacts on societal activity. Some conclusions are summarized in section 5 .

\section{Material and Methods}

Meteorological data used in this study come from three different data-sets which provide observationally based reference data (E-OBS and ERA-Interim) and simulation results (ENSEMBLES).

The following surface atmospheric variables have been considered: mean sea level pressure $(p s l)(\mathrm{hPa})$, minimum, maximum and mean surface temperature (tasmin, tasmax, tas) $\left({ }^{\circ} \mathrm{C}\right)$, total precipitation (pr) $(\mathrm{mm} /$ day) and wind speed (wind) $(\mathrm{m} / \mathrm{s})$.

The analysis domain extends between 31.785 $\mathrm{N} / 60.125 \mathrm{~N}$ and $7.125 \mathrm{~W} / 25.125 \mathrm{E}$ (Fig. 1).

Six sub-regions have been considered over this area to assess models' performances (Fig. 2): Alpine Region (ALP), Po Valley (POV), Central Italy (CIT), Southern Italy (SIT), Sardinia (SAR) and Sicily (SIC)

These sub-regions cover the diversity of main climate characteristics in Mediterranean region, ranging from alpine/continental climate in ALP/POV to maritime/arid climate conditions in SIT, SAR and SIC.

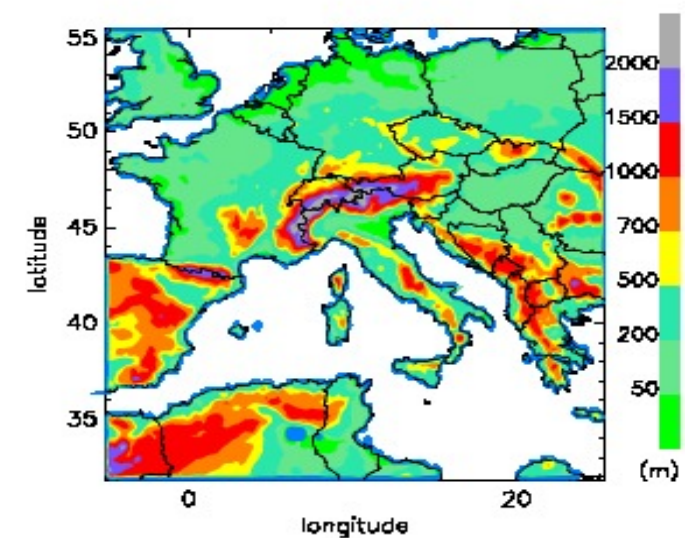

Fig. 1 Analysis domain with orography description. 


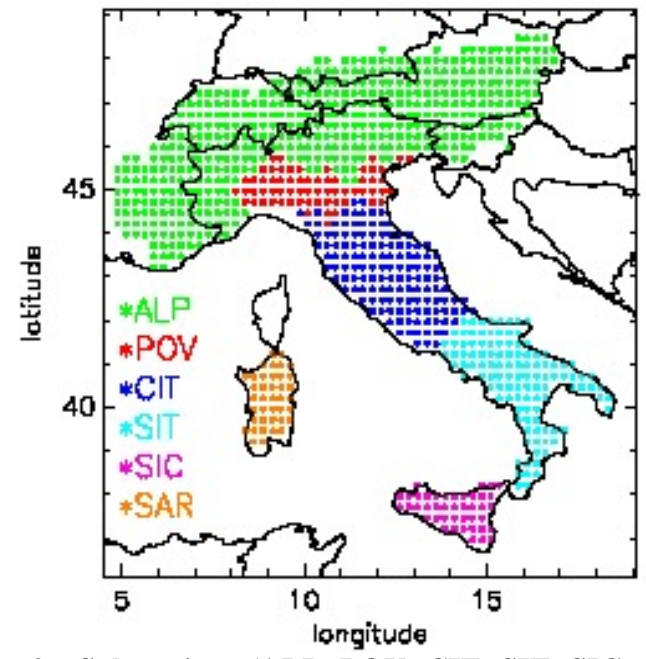

Fig. 2 Sub-regions (ALP, POV, CIT, SIT, SIC and SAR) identified by different colored grid-points.

An additional analysis has been performed focusing over ALP, POV and SIC sub-regions.

E-OBS (version 10.0) [14] is a daily gridded data set constructed from station data, consisting of daily temperature (mean, minimum and maximum values) and precipitation grid values over land at $0.25 \times 0.25$ degree resolution for the period 1961-2013.

ERA-Interim [15] is a reanalysis data-set at $1.5 \times 1.5$ degree resolution, based on observational data, prepared by the European centre for Medium-Range Weather Forecast (ECMWF). Horizontal wind components were downloaded every six hours (00:00, 06:00, 12:00, 18:00 GMT) for the period 1981-2010 and used to calculate daily wind speed.

ENSEMBLES is a very complex data-set consisting of several RCM runs, driven by different GCMs. Among the whole dataset, ten transient regional climate model runs have been selected with a horizontal resolution of $25 \mathrm{~km}$, at daily scale, for the period 1951 to 2050 (Table 1). This set of models and simulations consists of seven RCMs nested in five different driving GCMs, driven by the SRES A1B emission scenario [16].

The spread among model results has been investigated in several studies $[17,18]$ and points out that an accurate model reconstruction of climate change over complex orography is so far challenging. If the dependence of temperature with elevation may be difficult to describe, the relation of precipitation and winds with topography is even more complex, because of nonlinear interactions of processes at a wide range of spatial and temporal scales. In particular, a simple precipitation-height relationship does not exist on the Alpine scale, because much of the topographic signal is associated with slope and shielding, rather than height effects [19].

As the evaluation of the model error in reproducing the past climate is essential for a plausible description of future climate, the models' performances have been verified in the description of the climate in the last decades. Then some climate change projections have been elaborated by using a sub-set of models, whose results matched satisfactory E-OBS and ERA-Interim data.

Table 1 List of ENSEMBLES simulations used in this study and bold acronym indicate simulations used in the multi-model ensemble [7].

\begin{tabular}{llll}
\hline Driving GCM & RCM & Simulation & Acronym \\
\hline ARPEGE RM1 & Aladin & CNRM-RM5.1_ARPEGE & C-A \\
ARPEGE & HIRHAM5 & DMI-HIRHAM5_ARPEGE & D-A \\
BCM & HIRHAM5 & DMI-HIRHAM5_BCM & D-B \\
HadCM3Q0 & CLM & ETHZ-CLM_HadCM3Q0 & E-H \\
ECHAM5-r3 & ICTP-REGCM3 & ICTP-REGCM3_ECHAM5 & I-E \\
ECHAM5-r3 & RACMO & KNMI-RACMO2_ECHAM5 & K-E \\
HadCM3Q0 & HadRM3Q0 & METO-HC_HadCM3Q0 & M-H \\
HadCM3Q0 & RCA & SMHIRCA_HadCM3Q3 & S-H \\
ECHAM5-r3 & RCA & SMHIRCA_ECHAM5 & S-E \\
BCM & RCA & SMHIRCA_BCM & S-B \\
\hline
\end{tabular}


Daily data have been analyzed considering the following periods:

- reference period (REF)

1961-1990 as baseline of the climatic conditions;

- future scenario (FUT)

2021-2050;

- validation period (VAL)

1961-2013 for tas, tasmin, tasmax and pr;

1981-2010 for wind.

\section{Models' Performances Validation Criteria}

Many metrics have been proposed by the Program for Climate Model Diagnosis and Intercomparison [20-22]. Among many popular statistical measures that directly compare model simulations with observationally based reference data (mean error, root-mean square error, correlation and variance), here, the metric used is the BIAS index, calculated in the VAL period for the six sub-regions depicted in Fig. 2.

Models' validation has been performed by using regular grids with resolution identical to the reference data ones: the temperature and precipitation values provided by ENSEMBLES simulations were compared with E-OBS data on the $0.25^{\circ} \times 0.25^{\circ}$ grid for the period 1961-2013. Model wind speeds were evaluated against ERA-Interim reanalysis data after the climate model data have been resampled to a common grid of $1.5^{\circ} \times 1.5^{\circ}$ for the period 1981-2010.

Temperature and wind speed BIAS indexes were computed according the BIAS definition (Eq. (1)):

$$
B I A S=\bar{V}_{\text {mod }}-\bar{V}_{o b s}
$$

Where,

$$
\bar{V}_{\text {mod }}=\sum v_{\text {mod }} / n_{g} \quad \bar{V}_{o b s}=\sum v_{o b s} / n_{s}
$$

$n_{g}$ is the number of grid points used to calculate the model mean $\bar{V}_{\text {mod }}$ in the sub-region considered;

$n_{s}$ is the number of grid points used to calculated the reference mean $\bar{V}_{o b s}$ over the same grid area.
For precipitation the percentage BIAS values have been considered Eq. (2):

$$
B I A S_{p}=\left(\bar{V}_{\bmod }-\bar{V}_{o b s}\right) / \bar{V}_{o b s} \cdot 100 \%
$$

The comparison between models and reference data has been done keeping in mind that both E-OBS and ERA-Interim data may have some limitations in representing the real local climatic characteristics as often there are not enough observation stations at high altitudes [23].

E-OBS has been found to over-smooth both precipitation and temperature over complex topography, leading to a reduced area-averaged data [24].

ERA-Interim may present shortcomings in representing realistically local wind characteristic. This has been investigated by comparing the reanalysis data with SYNOP (surface synoptic observations) information (Fig. 3). The results point out that ERA-Interim values may underestimate wind over some mountain Italian sites even more than 50\% like Monte Cimone (2,173 m), Monte Terminillo (1,875 m), Passo Cisa $(1,040 \mathrm{~m})$. However, a full quantitative assessment of observational errors is beyond the scope of this study.

\section{Results and Discussion}

A models' performance analysis has been done in order to assess how a multi-model ensemble is able to captures reference spatial patterns in terms of the amplitude and phase of the seasonal cycle. Then model results have been analyzed to project changes in mean climate and about the occurrences of some severe weather events.

\subsection{Assessment of Models’ Performances}

Fig. 4 summarizes models' performances by visualizing annual BIAS indexes by means of horizontal gray bars for: tas, tasmin and tasmax (left column), pr (central column) and wind (right column) for each sub-region. 

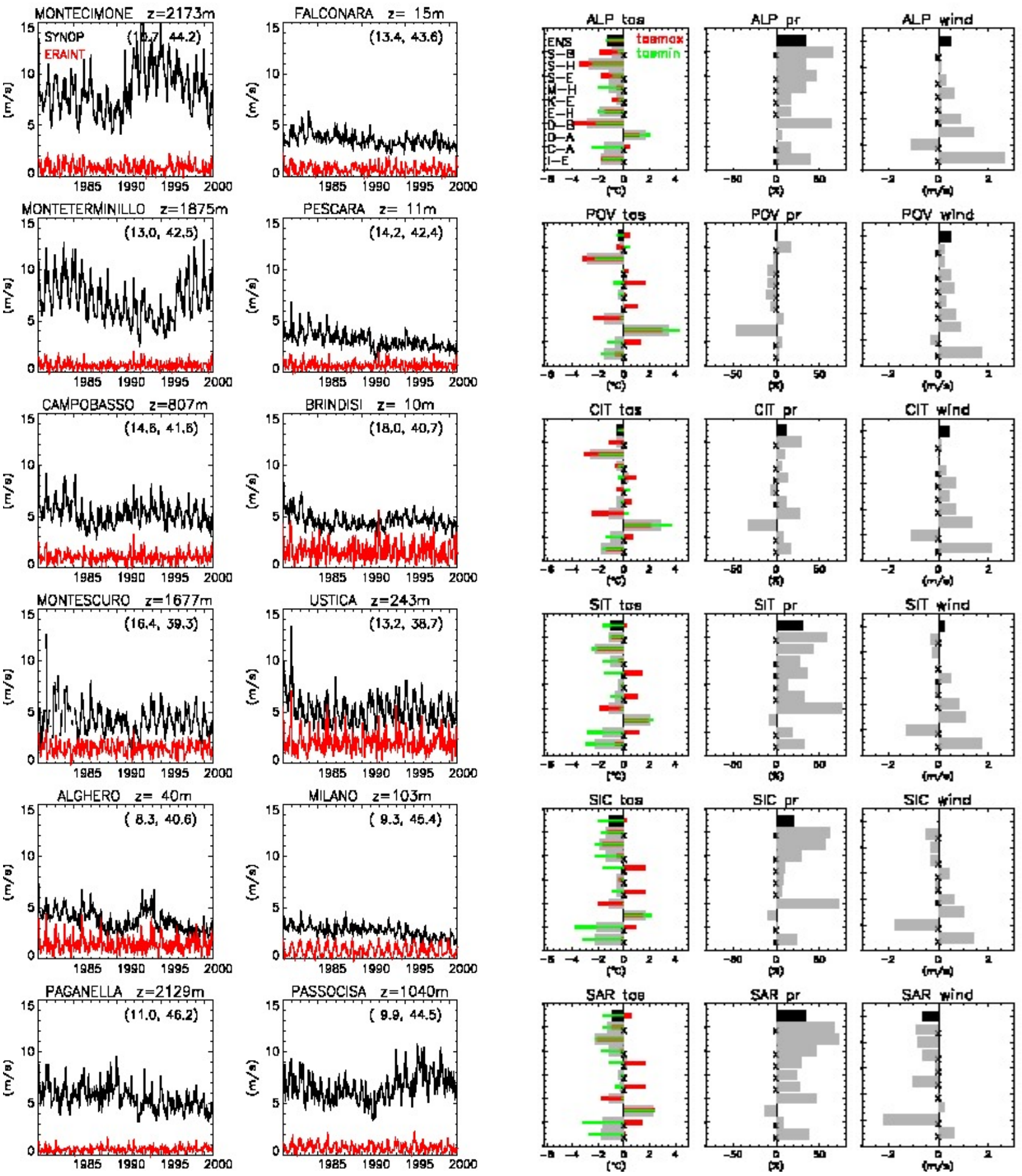

Fig. 3 Monthly mean wind speed recorded by some Italian SYNOP stations (black line) in comparison with ERA-Interim data (red line), for each station geographical coordinates are reported in (longitude, latitude).

Fig. 4 Models' BIAS indexes for: tas, tasmax (red bars) and tasmin (green bars) $\left({ }^{\circ} \mathrm{C}\right)$ (left column); $\mathrm{pr}(\%)$ (central) and wind $(\mathrm{m} / \mathrm{s})$ (right), the small black crosses indicate the models selected to compute ENS mean. 
As known, models' performances change with variable considered and/or with the region investigated, with a skill depending more on the variable than the region investigated.

Most of the models have negative tas BIAS indexes (cold bias) indicating that RCMs (apart D-A) underestimate temperature, in particular, over ALP area. Similar results affect the accuracy of tasmin and tasmax estimates.

Regarding precipitation, it is found a general overestimation (wet bias), except for the Po valley overall characterized by dry bias. RCMs overestimate wind speed over POV, ALP and CIT (with the exception of $\mathrm{C}-\mathrm{A}$ ), while they have different scores over the other sub-regions.

As Mediterranean region is characterized by a typical seasonal cycle, seasonal BIAS values have been calculated too. Wind speed BIAS values are invariant with respect to the seasons, whereas, temperature and precipitation indexes depend on them: generally areas with cold bias in winter exhibit wet biases, whereas, the relationship is reversed during summer. Models differ one from each other more in summer than in the other seasons because of the different surface scheme formulations, as mentioned in previous studies [25]. In particular, precipitation is known to be more independent from large-scale climate state than temperature, especially in summer, when rainfall events are mainly controlled by local-scale convective processes and other factors such as soil moisture.

Following the recommendations stated in the Program for Climate Model Diagnosis and Intercomparison [26], a multi-model ensemble mean has been computed to improve the accuracy and reliability of probabilistic projections compared to single model realizations. The underlying assumption is that uncertainties can be reduced if the results from the 'better performing' models are considered in the ensemble (labelled ENS hereinafter) to produce probabilistic projections. Therefore, ENS was calculated by considering only the models with law bias indexes in representing temperature, precipitation and wind speed in most cases. A sub-set of seven simulations was selected (C-A, E-H, I-E, K-E, M-H, S-B and S-E), whereas, the other three runs (D-A, D-B and $\mathrm{S}-\mathrm{H}$ ) were discarded because of their large bias values.

This sub-set reveals that three RCMs ( 3 out of 7 simulations) were forced by the GCM ECHAM5. Therefore, this particular global model is overweighed compared to the other three GCMs and even simple estimates for expected climate change and its uncertainty (such as ensemble mean or variability) are potentially biased towards the ECHAM5 climate response. As the uncertainty introduced by the driving GCM is generally larger than the other sources (emission scenario, different RCMs, member of the sample), this may represent a shortcoming in the selected model sub-set. However, it is worth noting that ECAHM5 is one of the top five GCMs well performing with regards the annual Model Performance Indexes of upper air and surface parameters of the CMIP3 ensemble [27].

Because the ensemble mean has the favorable characteristic of smoothing the higher frequency and smaller scale features, ENS values generally perform better than the individual models, as can be inferred from the black bars in Fig. 4, in accordance with previous studies [4, 9].

The robustness of the metric chosen has been verified by calculating also the Mean Absolute Error (MAE) index (Eq. (3)):

$$
M A E=\frac{1}{N} \sum_{k=1}^{N}\left|v_{\text {mod }}(k)-v_{o b s}(k)\right|
$$

Where, $N$ is the number of grid points used to compare model and reference values.

The results (not shown) indicate that models with large BIAS values (discarded in computing ENS) have MAE values of the same intensity, as affected by systematic errors, whereas, those with low biases (selected for ENS) have small MAE values too, 
confirming the criteria used to set up the sub-set is fairly good.

\subsection{Model Climate Reconstruction in the REF Period}

The maps in the Fig. 5 represent temperature, precipitation and wind fields at seasonal scale, in the order winter (DJF), spring (MAM), summer (JJA) and autumn (SON).

Confirming previous works [28], the multi-model ensemble reproduces reasonably well the typical spatial patterns for temperature (first row), precipitation (second row) and wind speed (third row), with signal essentially tied to the main topographical feature and land/sea interface. The lowest temperature values are in correspondence with the mountain peaks and the highest ones characterize the surrounding valley areas. The highest precipitation values are found over the
Alps, whereas, the lowest values are estimated over the Po valley and the southern areas, especially in summer. Strong winds characterize northern Europe regions, particularly in the cold months, instead low wind speeds are estimated for the Po valley above all during summer season.

With references to EOBS seasonal averages, ENS temperature values suffer from varying levels of systematic biases over mountain regions (not shown): most RCMs have cold biases over Alpine Region and, because this error is prevalent, discrepancies in temperature field affects also multi-model results with cold biases up to $-5{ }^{\circ} \mathrm{C}$ in cold months. Smaller underestimates are detectable in the rest of the Peninsula, save the Po valley and some small areas of Central and Southern Italy in the summer, where light overestimations (about $1^{\circ} \mathrm{C}$ ) have been found.
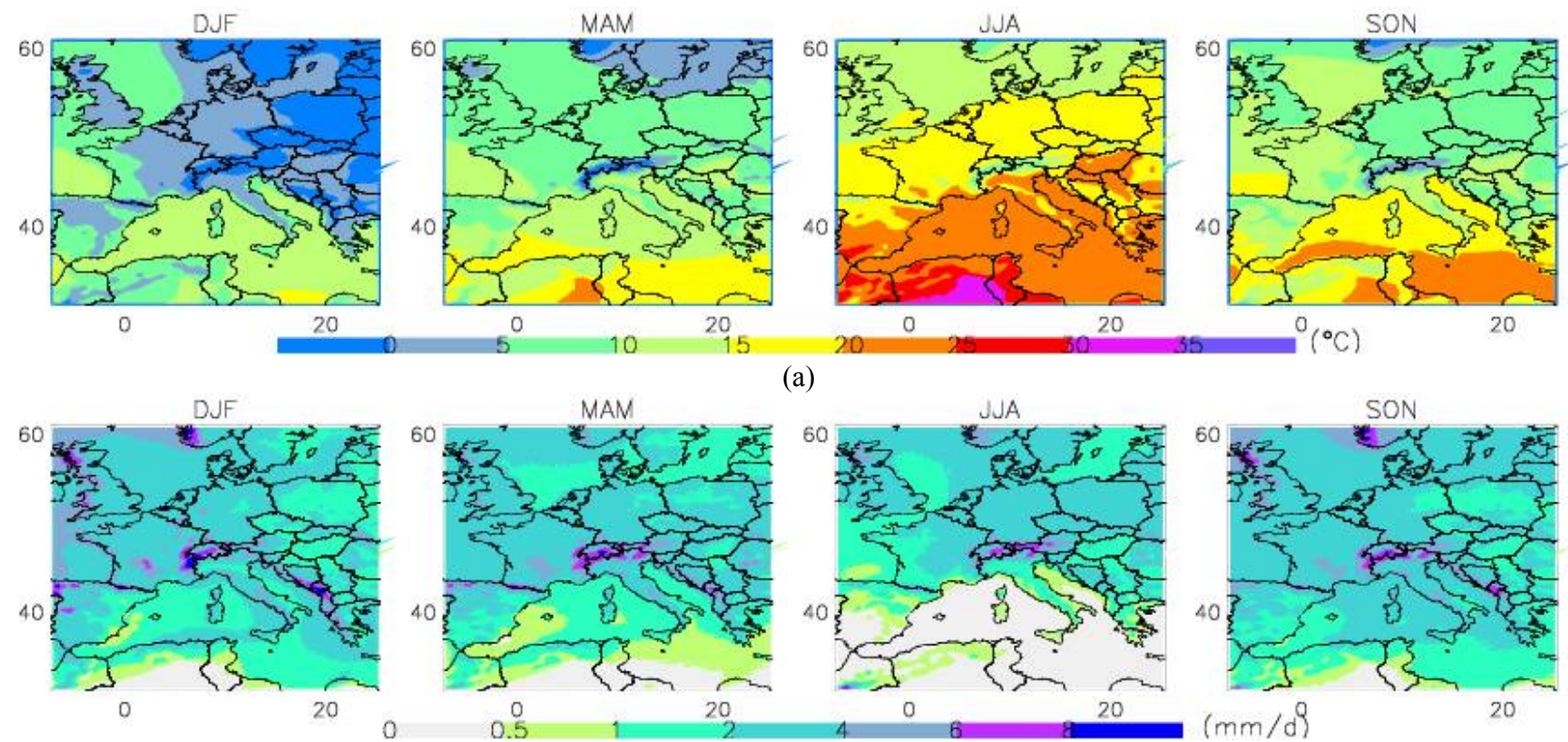

(a)
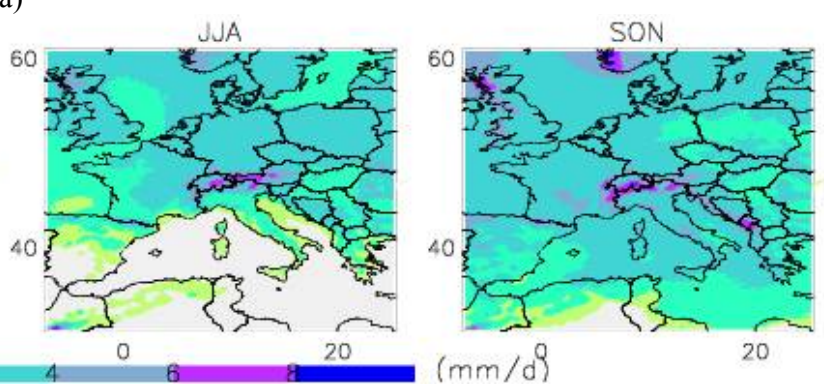

(b)
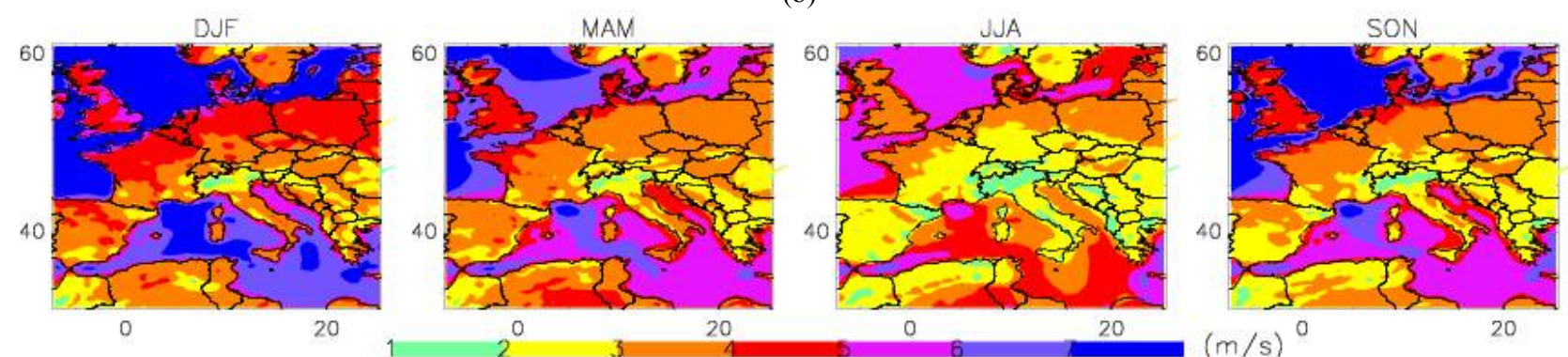

(c)

Fig. 5 Seasonal mean values provided by ENS in REF period for (a) temperature $\left({ }^{\circ} \mathrm{C}\right)$, (b) precipitation (mm/day) and (c) wind speed(m/s),in the order, from left to right, $\mathrm{DJF}=$ winter, $\mathrm{MAM}=$ spring, $\mathrm{JJA}=$ summer and SON $=$ autumn. 
ENS gives a reasonable representation of summer rainfalls, with most bias values ranging between -1 $\mathrm{mm} /$ day and $1 \mathrm{~mm} /$ day, except over the Alps where there is a slight tendency to overestimate precipitations (1-3 mm/day). In the others seasons, the comparison indicates: strong wet biases (up to $6 \mathrm{~mm} /$ day) over the Alps, slight overestimations on the Central and Southern Italy (1-2 $\mathrm{mm} /$ day) and a satisfactory agreement over flat areas of Northern and Central Italy. Generally, bias error are largely within $\pm 50 \%$ unless discrepancies over mountain regions with values exceeding $80 \%$.

Comparing the ENS wind speed values against ERA-Interim data, generally, the discrepancies are within $1 \mathrm{~m} / \mathrm{s}$ over the all sub-regions. The ENS estimates exceed $2 \mathrm{~m} / \mathrm{s}$ the reanalysis data over Alpine region during winter and spring. It is worth noting again that the model overestimations over the Alps could be misleading errors because of shortcomings in reference data.

\subsection{Future Projections of Seasonal Scenarios}

Seasonal future projections have been elaborated for the period 2021-2050 in terms of anomalies, computed by the difference between the FUT and REF scenarios. Fig. 6 represents the spatial patterns of expected seasonal average changes for $p s l$, tas, $p r$ and wind.

In accordance with former assessments [3], psl changes are characterized in winter by an increased anticyclonic circulation centered over Southern Italy and, in other seasons, by an increased high sea level pressure extending from the North-Eastern Atlantic to Mediterranean, implying some deviation of westerly winds towards Northern Europe and a northward shift of the Atlantic storm track.

The whole Mediterranean region is expected to experience an increase of temperature in all seasons (1-1.5 ${ }^{\circ} \mathrm{C}$ at least), with the largest increase in summer (about $2-2.5{ }^{\circ} \mathrm{C}$ ) especially in inland and southern Mediterranean areas, in agreement with previous findings [29]. Moreover, it is highlighted a likely warming of about $1.5^{\circ} \mathrm{C}$ over Alpine region in winter season.

Regarding precipitation, the change projected has a dipolar structure, with an increase in precipitation over the northern Europe and a reduction over the Mediterranean basin where a seasonal variation is detectable: in winter precipitation is projected to increase over North Italy, whereas, an east-west dipolar pattern is expected over the rest of the Peninsula. A substantial general decreasing in precipitation is likely in the summer, in particular, a mean reduction of about $20 \%$ is assessed in the Southern of Italy and over Sicily. These results confirm previous study gathered from CMIP3 global and PRUDENCE regional model experiments [30].

ENS projections point out a light decrease of wind in the Southern of Alpine Region, the opposite in the North. Because of wide model spread (standard deviation fields are generally greater than the change projected), it is difficult to infer a clear signal. Even if confidence in future changes in windiness is relatively low [31], it is likely a decrease of wind in projected increased anticyclonic conditions, as the surface wind changes are determined mainly by large scale free atmosphere circulation.

Table 2 summarizes the results for all sub-regions by reporting at annual scale the mean values in REF period, the anomalies (ANM) between FUT and REF periods, the standard deviations (STD) in FUT period for tas, tasmax, tasmin, $p r$ and wind.

\subsection{Characterization of Intense Events}

It is recognized an increasing risk for extreme events in the future, especially heat waves, wind storms, heavy rainfall and droughts, are likely to increase in intensity and frequency [32, 33].

Since extreme events are typically rare events, only limited observational data are available for their study. Climate models exhibit a correspondingly large uncertainty in their simulation, especially for non-temperature related extremes. 

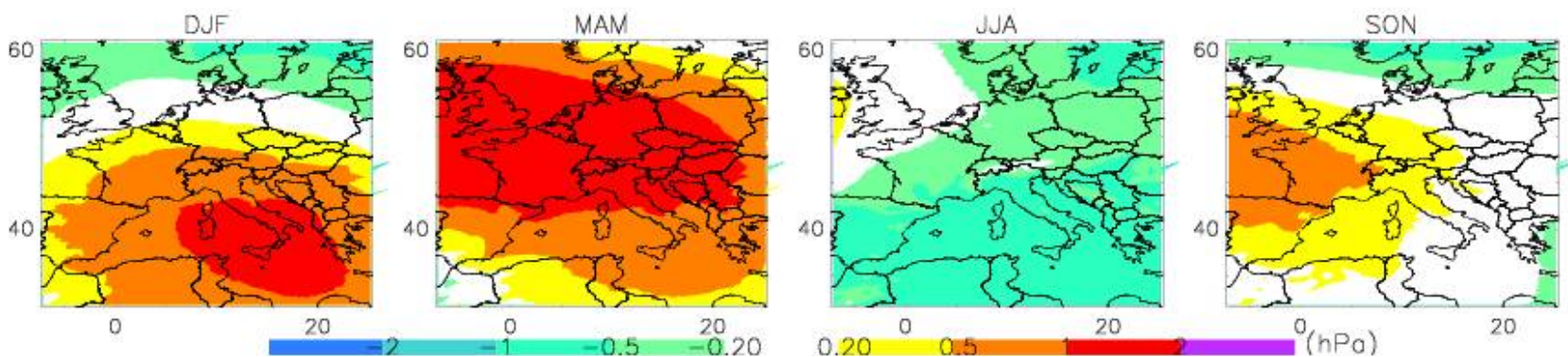

(a)
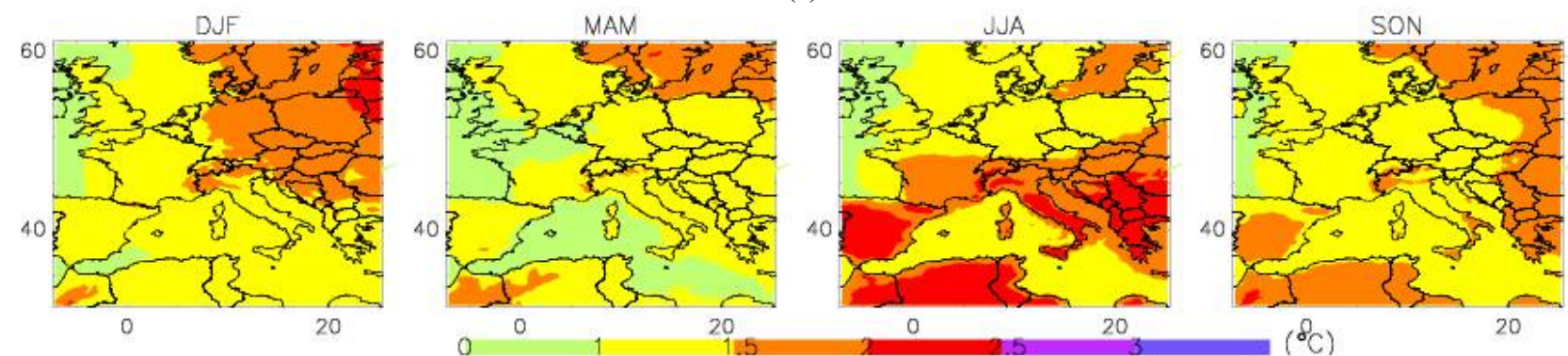

(b)
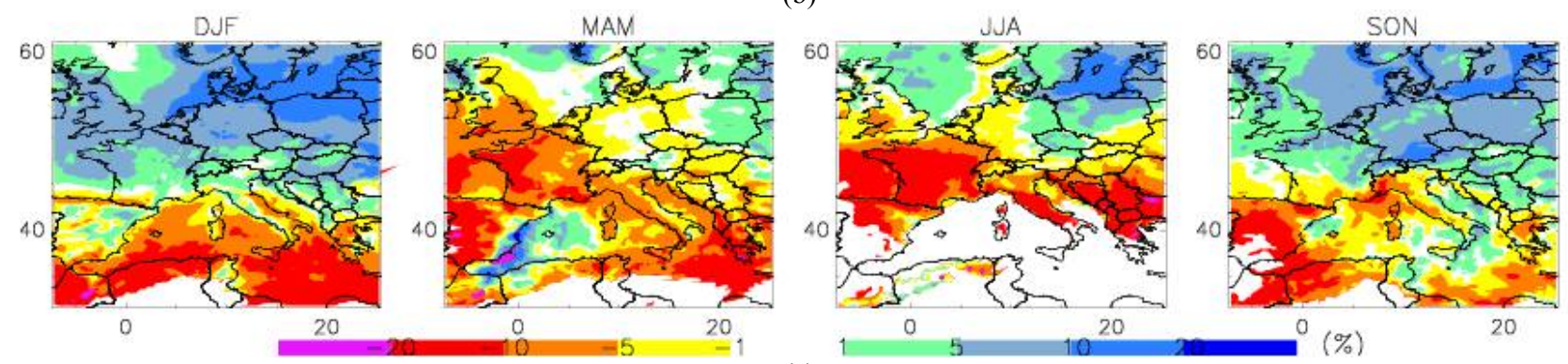

(c)
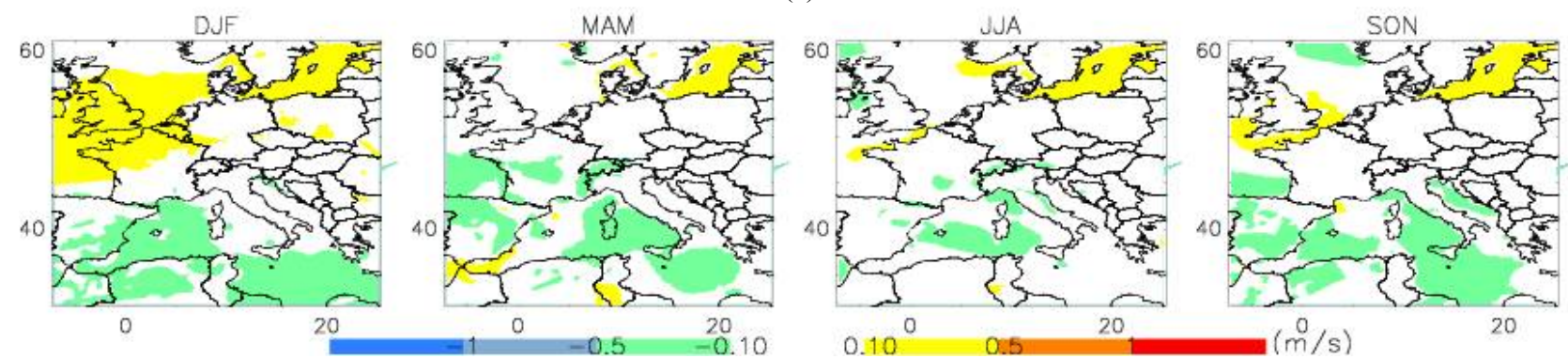

(d)

Fig. 6 Future seasonal mean climate change projected by 2021-2050 relative to the 1961-1990 base period for: (a) pressure (hPa), (b) temperature $\left({ }^{\circ} \mathrm{C}\right),(\mathrm{c})$ precipitation (\%) and (d)wind speed (m/s).

Table 2 Average reference values (AVG), future anomalies (ANM) and standard deviation (STD) of temperature (tas, tasmin and tasmax), precipitation (pr) and wind speed (wind) for the six sub-regions considered in this study, for each sub-region the mean orography $(\mathrm{m})$ is report in the column orog.

\begin{tabular}{|c|c|c|c|c|c|c|c|c|c|c|c|c|c|c|c|c|c|}
\hline \multirow{3}{*}{$\begin{array}{l}\text { Sub- } \\
\text { region }\end{array}$} & \multirow{3}{*}{$\begin{array}{l}\text { orog } \\
\text { (m) }\end{array}$} & \multicolumn{3}{|c|}{$\operatorname{tas}\left({ }^{\circ} \mathrm{C}\right)$} & \multicolumn{3}{|c|}{$\operatorname{tasmax}\left({ }^{\circ} \mathrm{C}\right)$} & \multicolumn{3}{|c|}{$\operatorname{tasmin}\left({ }^{\circ} \mathrm{C}\right)$} & \multicolumn{4}{|c|}{$p r(\mathrm{~mm} / \mathrm{d})$} & \multicolumn{3}{|c|}{ wind $(\mathrm{m} / \mathrm{s})$} \\
\hline & & \multirow{2}{*}{$\begin{array}{l}\text { REF } \\
\text { AVG }\end{array}$} & \multicolumn{2}{|c|}{ FUT } & \multirow{2}{*}{$\frac{\text { REF }}{\text { AVG }}$} & \multicolumn{2}{|c|}{ FUT } & \multirow{2}{*}{$\frac{\text { REF }}{\text { AVG }}$} & \multicolumn{2}{|c|}{ FUT } & \multicolumn{2}{|l|}{ REF } & \multicolumn{2}{|l|}{ FUT } & \multirow{2}{*}{$\begin{array}{l}\text { REF } \\
\text { AVG }\end{array}$} & \multicolumn{2}{|c|}{ FUT } \\
\hline & & & ANM & STD & & ANM & STD & & ANM & STD & AVG & ANM & ANM\% & STD & & ANM & STD \\
\hline OVV & 212 & 12.1 & 1.5 & 0.53 & 17.4 & 1.6 & 0.59 & 7.5 & 1.5 & 0.49 & 2.4 & -0.10 & -4.24 & 0.20 & 2.2 & -0.01 & 0.06 \\
\hline ALP & 1.050 & 5. & 1.5 & 0.50 & 10.3 & 1.5 & 0.54 & 1.9 & 1.6 & 0.49 & 4.3 & -0.06 & & 0.22 & 2.5 & -0.04 & 0.05 \\
\hline CIT & 429 & 11.9 & 1.5 & 0.50 & 16.9 & 1.6 & 0.56 & 7.4 & 1.5 & 0.46 & 2.6 & -0.14 & & 0.19 & 2.8 & -0.01 & 0.07 \\
\hline SIT & 379 & 13.3 & 1.5 & 0.49 & 18.4 & 1.6 & 0.46 & 8.9 & 1.5 & 0.46 & 2.2 & -0.11 & -5.09 & 0.17 & 3.0 & -0.01 & 0.08 \\
\hline SIC & 393 & 14.5 & 1.5 & 0.51 & 19.9 & 1.6 & 0.58 & 9.8 & 1.5 & 0.47 & 1.7 & -0.14 & -8.33 & 0.17 & 3.1 & -0.04 & 0.08 \\
\hline SAR & 321 & 14.2 & 1.4 & 0.51 & 19.4 & 1.5 & 0.60 & 9.6 & 1.4 & 0.46 & 1.8 & -0.12 & -6.59 & 0.18 & 3.2 & -0.01 & 0.09 \\
\hline
\end{tabular}


Focusing on the European continent, a number of studies with regional climate models deal with future changes in extreme events $[34,35]$.

In this study, the possible changes in the distribution of intense events have been studied by analyzing some percentile maps and throughout a simple probabilistic approach.

\subsection{Change Patterns of Percentiles Seasonal Values}

To characterize intense events, the probability distribution functions (PDFs) of both temperature and precipitation have been considered: the 10th $(10 p)$, 90th (90p) and the 99th (99p) percentiles (for precipitation only) fields have been computed over the PDFs for each point of the analysis domain.

The percentile anomaly maps (not shown for sake of brevity) have spatial patterns similar to mean seasonal features (Fig. 3) but with some emphasized structures: tas $10 p$ fields are characterized by an increasing of $1-1.5^{\circ} \mathrm{C}$ on the whole Italian Peninsula in all seasons with the greatest increasing $\left(1.5-2{ }^{\circ} \mathrm{C}\right)$ in winter over mountain areas; the tas $90 \mathrm{p}$ change projections describe an overall warming of $1.5-2{ }^{\circ} \mathrm{C}$, with the most serious changes in summer with values reaching $2-2.5{ }^{\circ} \mathrm{C}$, up to $3{ }^{\circ} \mathrm{C}$ over some spot POV locations. Anomaly percentile patterns of minimum and maximum temperature indicate some more marked signals: tasmin $10 p$ highlights a warming ranging from $1{ }^{\circ} \mathrm{C}$ up to $3{ }^{\circ} \mathrm{C}$ moving from South-West to North-East Europe, in particular, an increasing of $1.5-2.5^{\circ} \mathrm{C}$ over ALP; tasmax 90p points out a temperature increasing of about $2-2.5^{\circ} \mathrm{C}$ over the whole Mediterranean region.

In order to prevent models' variability be artificially damped, the ensemble of the PDF has been also analyzed: in this case the increasing temperature is emphasized of an extra $1{ }^{\circ} \mathrm{C}$.

The fields pr 90p and pr 99p have been computed by considering only wet days (with precipitation exceeding $1 \mathrm{~mm} /$ day): pr 90p values highlight an increasing (about 10\%) of intense precipitation mostly over coastal areas during winter and fall seasons; $p r$
$99 p$ field, representative of very intense events, indicates an increasing of about $20 \%$ over the same sub-regions and highlights a still more pronounced positive tendency over the most of Northern Europe.

\subsection{Weather Events Characterization}

A lot of meteorological events (typically precipitations/wind regimes) and, especially, extreme events (as heavy precipitations or strong winds) are characterized by fields with high spatial-temporal variability [36].

The ENSEMBLES models are not expected to represent extreme weather events with the intensity and frequency comparable to what is observed (particularly for wind and precipitation-related events), because of their finite and still relatively coarse resolution. Nevertheless, they can give some information about the areas more likely vulnerable to severe weather events by characterizing spatial patterns interested by an high frequency of their occurrence.

With the assumption that significant changes in extremes is mostly based on exceedance numbers of moderate thresholds (such as a change in heavy precipitations is based on computing the number of days with precipitation higher than $10 \mathrm{~mm}[37,38])$, a simple probabilistic approach has been implemented to investigate some high-impact phenomena. A particular weather event has been selected by a threshold value, fixed lower than the typical one used to classify an extreme event but high enough to select a peculiar atmospheric phenomenon. Then vulnerable areas have been identified in case of a fair confidence in the modeled event occurrences.

According the confidence terminology defined by the Intergovernmental Panel on Climate Change [39], medium and high confidence have been obtained if models agree in the sign of the mean change at least $50 \%$ and $90 \%$ respectively. Since ENS sub-set consists of $N=7$ runs, medium and high confidences require a minimum agreement of 4 simulations and 6 simulations respectively. 
For each grid point $(\cdot)$ and for each seasons, the occurrence change $A F U T_{i, s}(\cdot)$ has been computed in percentage values (\%) for each model $i=1, N$ according to Eq. (4):

$$
\operatorname{AFUT}_{i, s}(\cdot)=100 \frac{N F U T_{i, s}(\cdot)-N R E F_{i, s}(\cdot)}{N R E F_{i}(\cdot)}
$$

Where, $N F U T_{i, s}(\cdot)$ and $N R E F_{i, s}(\cdot)$ are the occurrences in the FUT and REF scenarios, estimated by the model $\mathrm{i}$ in the seasons respectively.

The change direction was classified in two types depending on the sign of $\operatorname{AFUT}_{i, s}(\cdot)$ :

$$
\begin{aligned}
& S_{p, S}(\cdot)=\frac{1}{N} \sum_{i=1}^{N} \theta\left(\operatorname{AFUT}_{i, S}(\cdot)\right) \\
& S_{n, S}(\cdot)=\frac{1}{N} \sum_{i=1}^{N} \theta\left(-\operatorname{AFUT}_{i, S}(\cdot)\right)
\end{aligned}
$$

Where,

$$
\theta(X)=\left\{\begin{array}{l}
1 \text { if } X>0 \\
0 \text { if } X<0
\end{array}\right.
$$

$S_{p, s}(\cdot)$ and $S_{n, s}(\cdot)$ span a range from 0 to 1 .

If $S_{p, s}(\cdot)$ or $S_{n, s}(\cdot)>0.5$ most models agree in projecting respectively an increase or decrease of the event, then a relatively robust change is identified.

The weather event seasonal changes $\left\langle\operatorname{AFUT}_{s}(\cdot)\right\rangle$ have been estimated by Eq. (7):

$$
<A F U T_{S}(\cdot)>\stackrel{\text { def }}{=}<N R E F_{S}(\cdot)>\frac{\sum_{1}^{N e f f} A F U T_{i, S}(\cdot)}{N_{e f f}}
$$

Where, $\left\langle\operatorname{NREF}_{\mathrm{s}}(\cdot)\right\rangle$ is the mean seasonal occurrence provided by most coherent models (Neff $\geq$ 4). Conversely, no trend can be given with sufficient confidence.

Likely changes of some high-impact phenomena are represented in the Figs. 7-10 by different colors according the corresponding legend values, otherwise gray shades the maps. If nearly $90 \%$ of the models agree on the sign of the change (no less than 6 simulations), then the grid cell is stippled in the same figures to indicate very likely changes.

Precipitation events greater than $20 \mathrm{~mm}$ /day have been selected to identify areas likely interested by heavy precipitations.
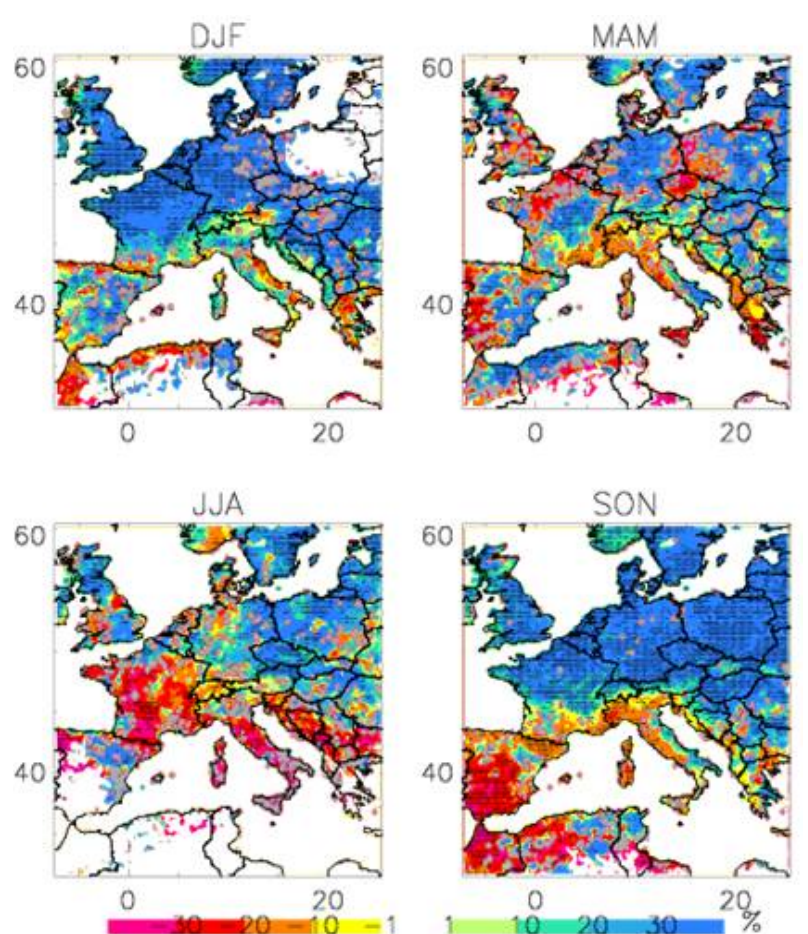

Fig. 7 Likely changes of events (\%) with daily precipitations greater than $20 \mathrm{~mm} / \mathrm{day}$ projected by 2021-2050, relative to 1961-1990 scenario, inferred by seven ENSEMBLES models (gray shades the figures if most models don't agree on the sign of change, grid cells are stippled in case of very likely changes, i.e. agreement with no less than 6 simulations over 7).

Fig. 7 indicates the percentage changes in the occurrence of heavy precipitations: by the mid-21st century most of Central-North Europe results likely vulnerable with an increase above $40 \%$ in all season. Focusing over Italy, the Central-North areas in winter, the South-Eastern coastal sites in spring and most of the Eastern Italian Peninsula during autumn will be interested by an increase up to $30 \%$.

The occurrence of windy days in the next decades has been characterized using a threshold value of $5 \mathrm{~m} / \mathrm{s}$ (Fig. 8).

A general strengthening (5\%-10\%) of windy events is projected over the Central-North Europe (above all in winter), whereas, a general decreasing of such events is expected over Southern Europe and, in particular, over Italy.

The capability to reproduce storminess is fundamental above all for local coastal management, in order to deal 

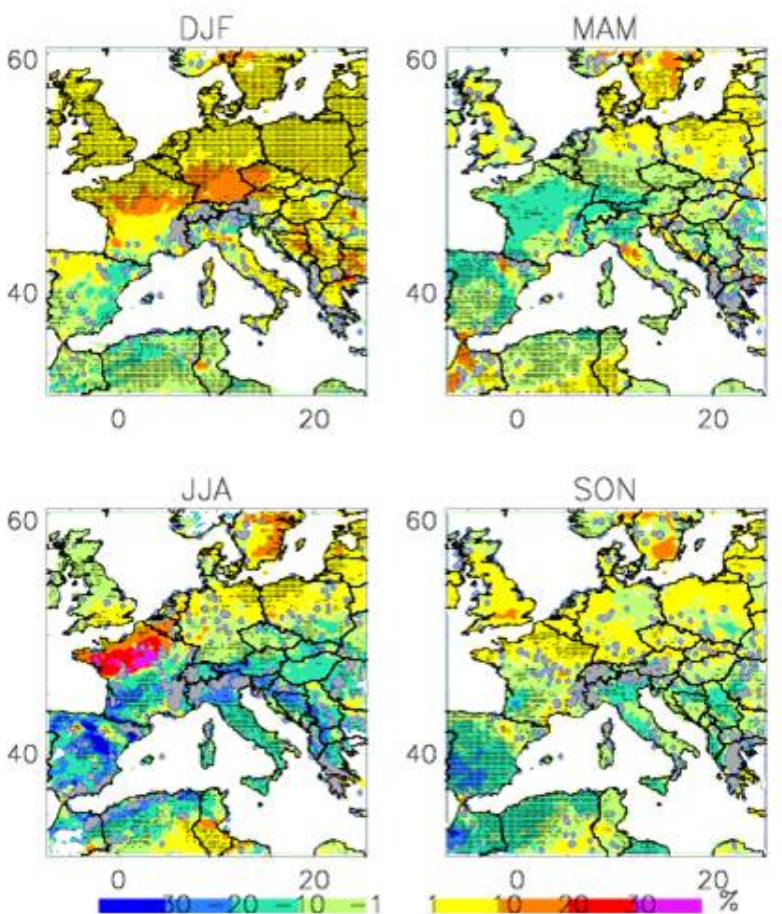

Fig. 8 As Fig. 7 but for percentage (\%) changes of windy events with daily speed $>5 \mathrm{~m} / \mathrm{s}$.

with threats like coastal flooding and severe erosion events. In this study, the changes in storm frequency have been characterized by selecting the simultaneous occurrence of wind speeds exceeding $5 \mathrm{~m} / \mathrm{s}$ and precipitations greater than $10 \mathrm{~mm} /$ day. The projections give a serious increasing risk (at least of 30\%-40\%) over Central-North Europe during winter and fall seasons, while in the other seasons some spot areas may be interested by such events. Regarding Italy, Tyrrhenian coasts in the winter, Adriatic coastal areas and Ionic regions in spring are identified as vulnerable areas (Fig. 9).

The occurrence of winter precipitation with high temperature have been investigated because they concern rainfall event of wet-snow, instead of snow events, that are the typical meteorological conditions for flooding events or avalanche days, as well as serious threats for overhead lines safety. In this case, the days characterized by the simultaneous occurrence of precipitation greater than $10 \mathrm{~mm} /$ day and maximum temperature values in the range $[-1.0,1.5]^{\circ} \mathrm{C}$ have been considered. The analysis (Fig. 10) gives an increase,
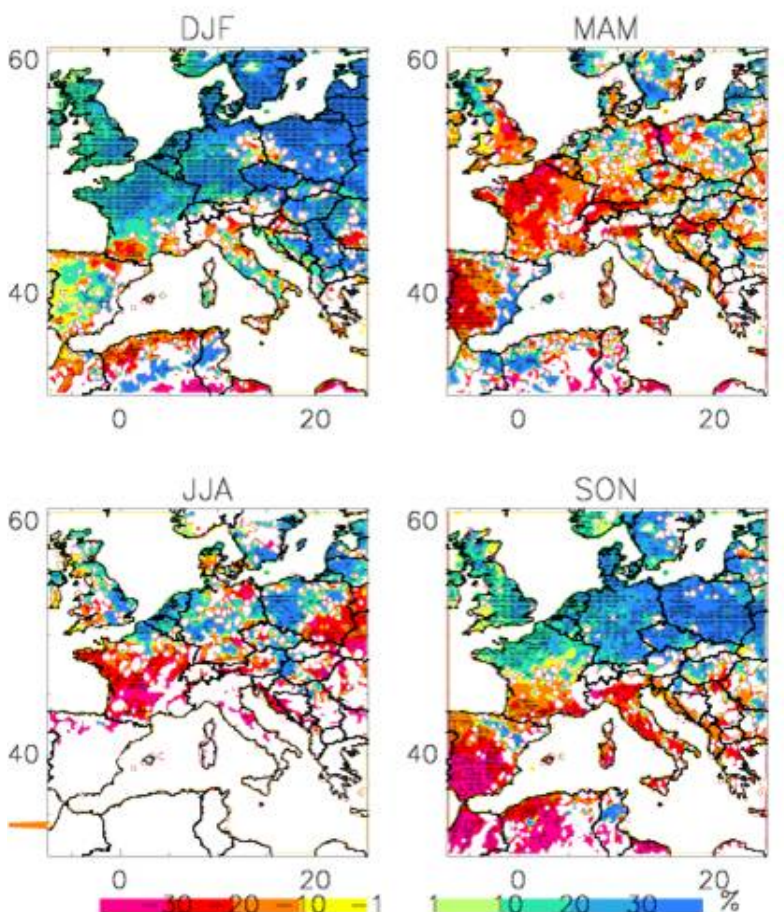

Fig. 9 As Fig. 7 but for percentage (\%) changes of meteorological events $(\%)$ with daily precipitation $>10$ $\mathrm{mm} /$ day and daily speed $>5 \mathrm{~m} / \mathrm{s}$.
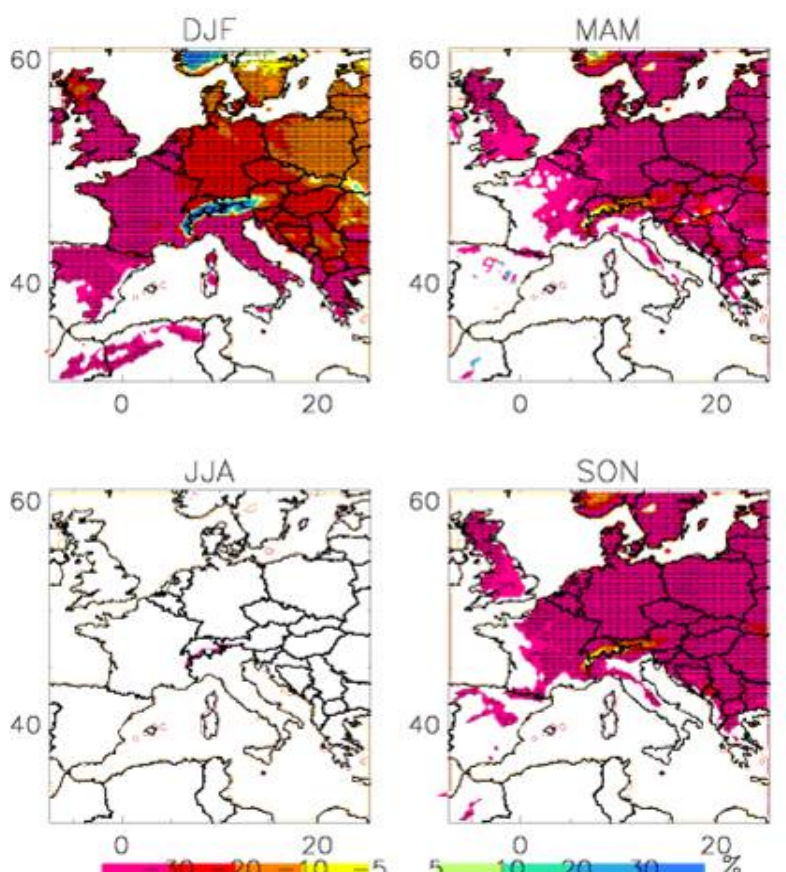

Fig. 10 As Fig. 7 but for percentage (\%) changes of wet-snow events (\%): daily precipitation $>10 \mathrm{~mm} /$ day and maximum temperature values ranging $[-1.0,1.5]^{\circ} \mathrm{C}$.

even more than $40 \%$, of rainfall/wet-snow events over Alpine region and several areas of Northern and 
North-East Europe in the winter, whereas, in the other seasons (in particular in spring), a decreasing is expected because of the associated increase in temperature.

\subsection{Climatic Changes over Sub-regions}

Because of remarkable climatic differences among the six sub-regions considered (Fig. 2), a climatic investigation has been computed for each one by aggregating meteorological values of the related grid points. The average values have been analyzed by computing ENS daily data, without neglecting distinctly model outputs to capture the range of uncertainty of the results.

Fig. 11 shows tas annual anomalies relative to 1961-1990 averages (analogous results were found for tasmin and tasmax): six panels (one for each sub-region) show E-OBS averages (black dots) and the corresponding ensemble means (red line).

To give an idea of whether the fluctuations are meaningful, confidence intervals from $5 \%$ to $95 \%$ of the simulated temperature for each decade from 1961 to 2050 are reported (light gray shading).

Moreover, linear regressions for E-OBS and ENS data are visualized in different colors in three periods and the rates $\left({ }^{\circ} \mathrm{C}\right.$ per decade) are reported. The simulated annual time series compare rather well with the observations in the different sub-regions, consistent with warming, although in the last two past decades the simulated temperature growth is slower than EOBS reconstruction, especially in the Po valley.

The simulated projections highlight a temperature increasing in the next decades with a warming over $2{ }^{\circ} \mathrm{C}$ by 2050 in all sub-regions. Note the temperature rate $\mathrm{R}$ is expected greater in the future, indicating accelerated warming.

Here some additional results are presented for ALP, POV and SIT areas, particularly interesting for the energy demand and production in Italy (analogous outcomes have been found for the other sub-regions).

Diagrams in Figs. 12-13 describe inter-monthly
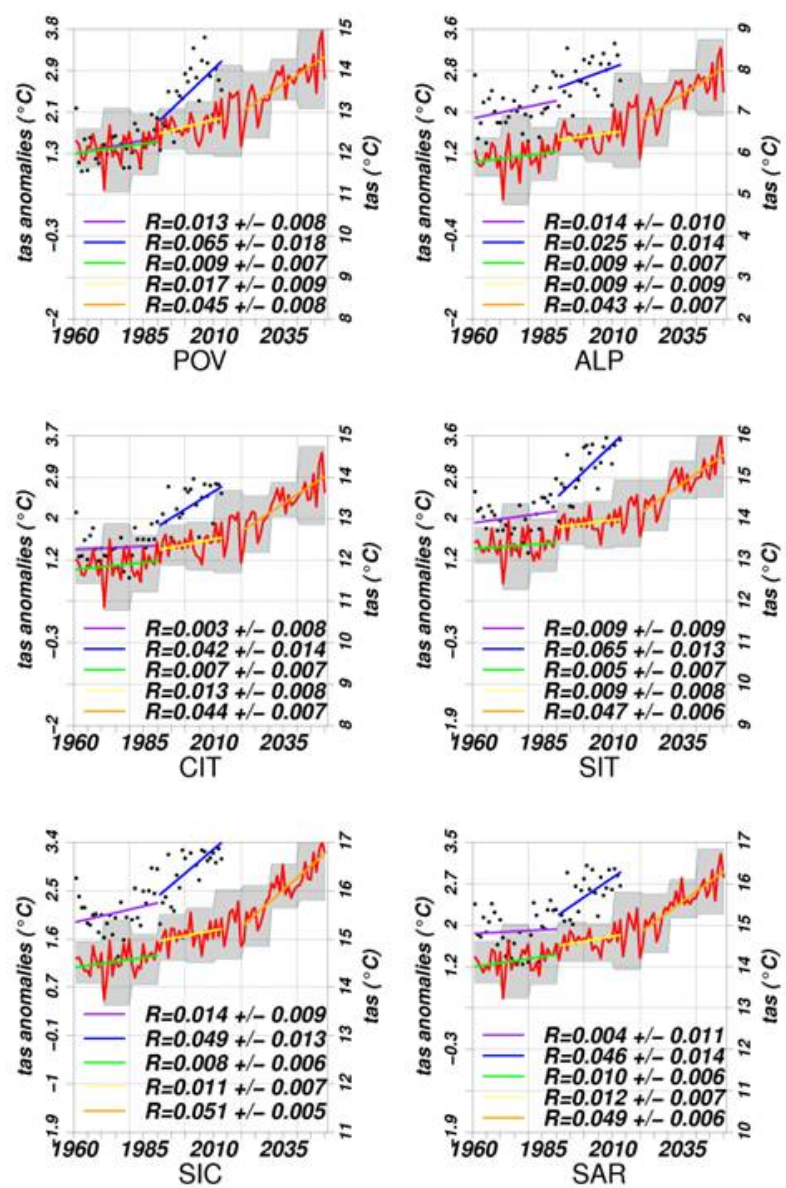

Fig. 11 Tas annual anomalies from 1961 to 2050 relative to 1961-1990, for the six sub-regions, provided by ENS (red line) and E-OBS values (black dots) (light gray shades the $5 \%-95 \%$ confidence intervals of the simulated anomalies for decade, E-OBS and ENS linear trends are drawn in different colors and the corresponding rates $R\left({ }^{\circ} \mathrm{C}\right.$ per decade) are reported).

variability and seasonal variations projected for tas (left column), pr (central column) and wind (right column) over ALP (a), POV (b) and SIT (c).

In the Fig. 12, horizontal gray bars represent monthly ENS anomalies between FUT and REF periods. The ranges of model estimates are represented by thin black bars overlapping on them to have a measure of the uncertainty in the simulated change signals.

Regarding temperature, the spread among models, lower than anomaly values, indicates robustness of the simulated signal, confirming an unambiguous increase of temperature (within an average range of $1{ }^{\circ} \mathrm{C}-2{ }^{\circ} \mathrm{C}$ ), above all in summer, over all sub-regions. Precipitation 

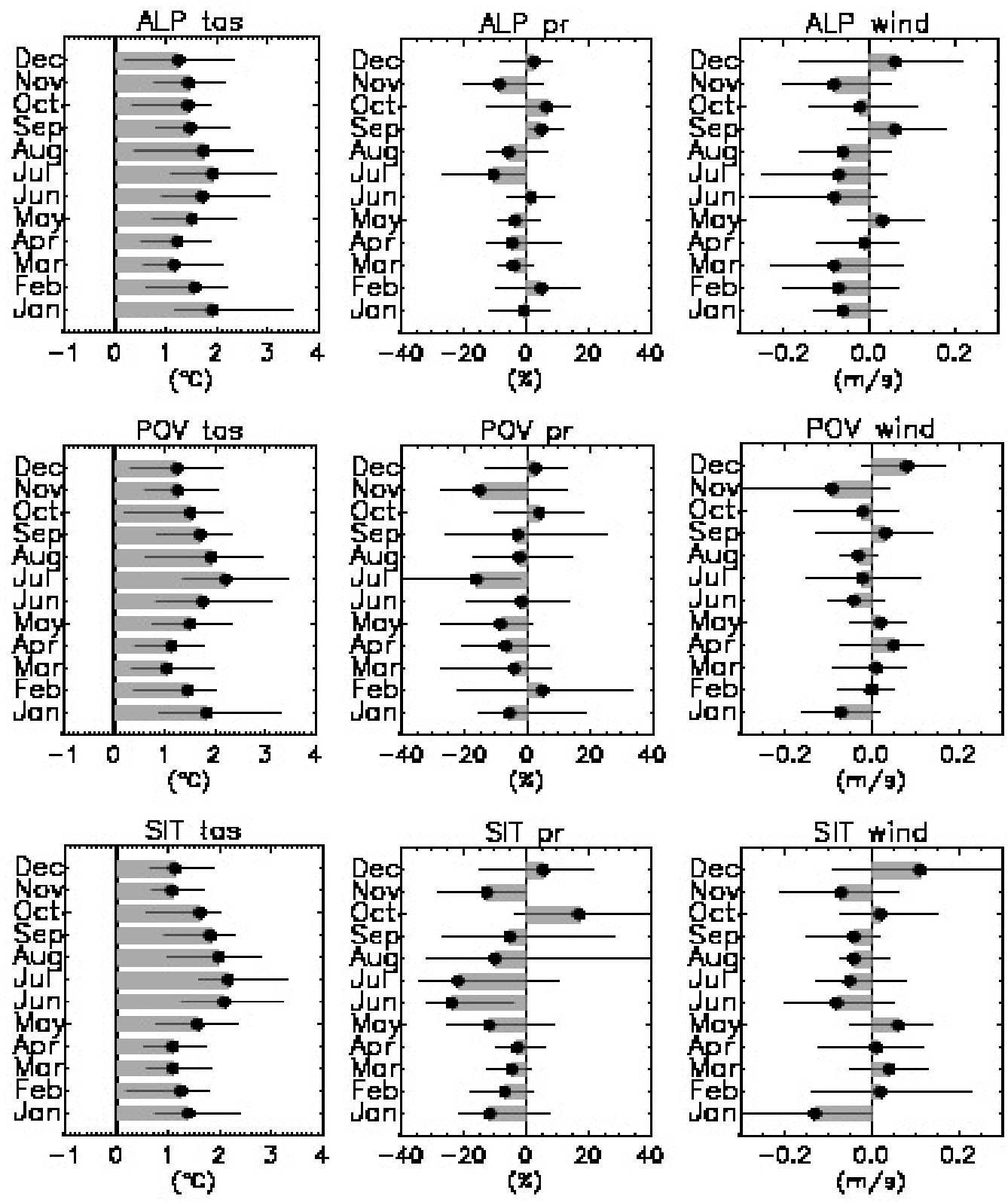

Fig. 12 Monthly anomalies for tas $\left(\left({ }^{\circ} \mathrm{C}\right)\right.$ left column), pr $((\%)$ central $)$ and wind $((\mathrm{m} / \mathrm{s})$ right) projected by $2021-2050$ relative to 1961-1990 elaborated by ENS over ALP, POV and SIT, thin black bars represent the range of the anomalies provided by the models used to compute ENS results.

and wind anomalies are of more difficult interpretation because the range of changes described by the different models is generally greater than the mean signal. However, the negative anomalies of precipitation during summer months are not to be neglected over SIT sub-region.

To investigate the changes not only in seasonal mean but also in seasonal extremes, an analysis method has been adopted: the PDF anomalies distribution relative to REF monthly means have been analyzed at seasonal scale [30]. Instead of the PDF of ENS anomalies, the ensemble of the PDFs (MED hereinafter) of the seven selected models has been considered to capture the range of the changes resulting from the different models.

Diagrams in the Fig. 13 represent in three columns the PDFs of tas, $p r$ and wind seasonal anomalies in the REF and FUT periods (from the top to the bottom: DJF, 

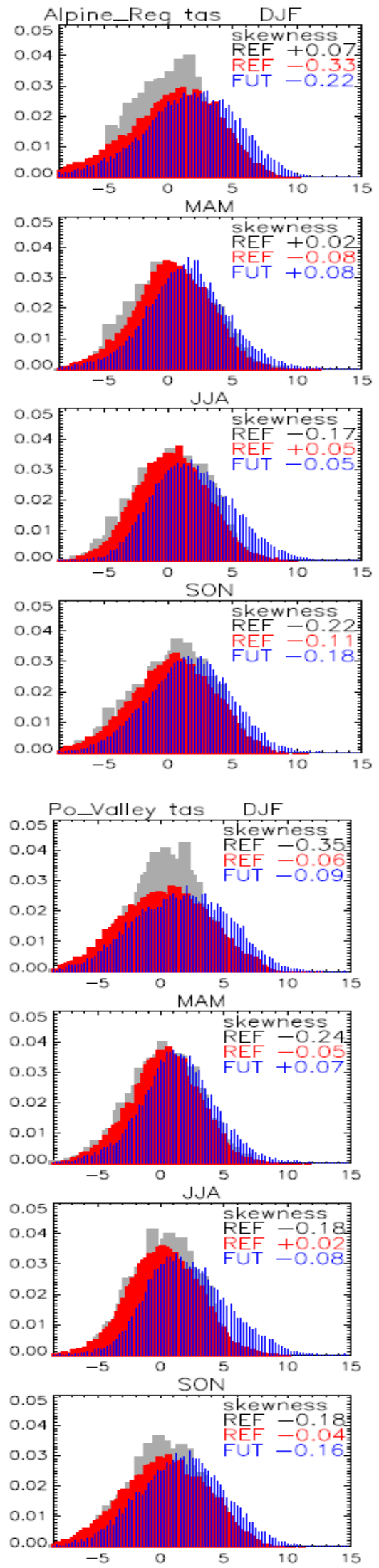
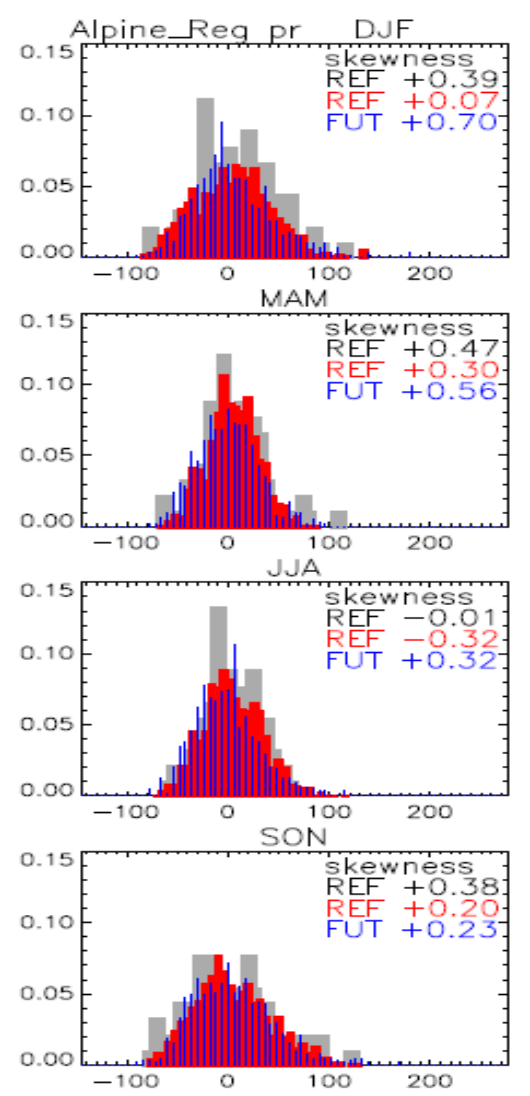

(a)
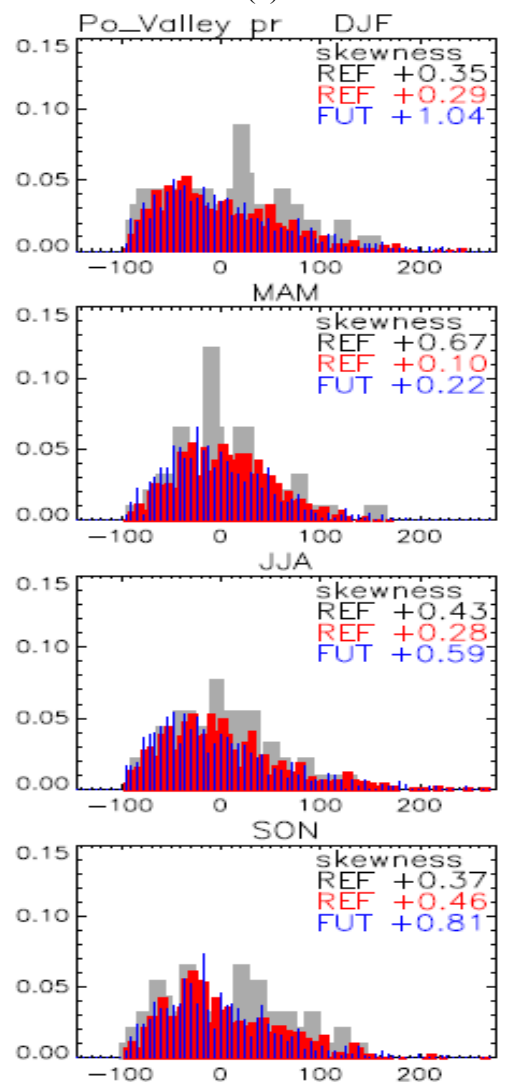

(b)
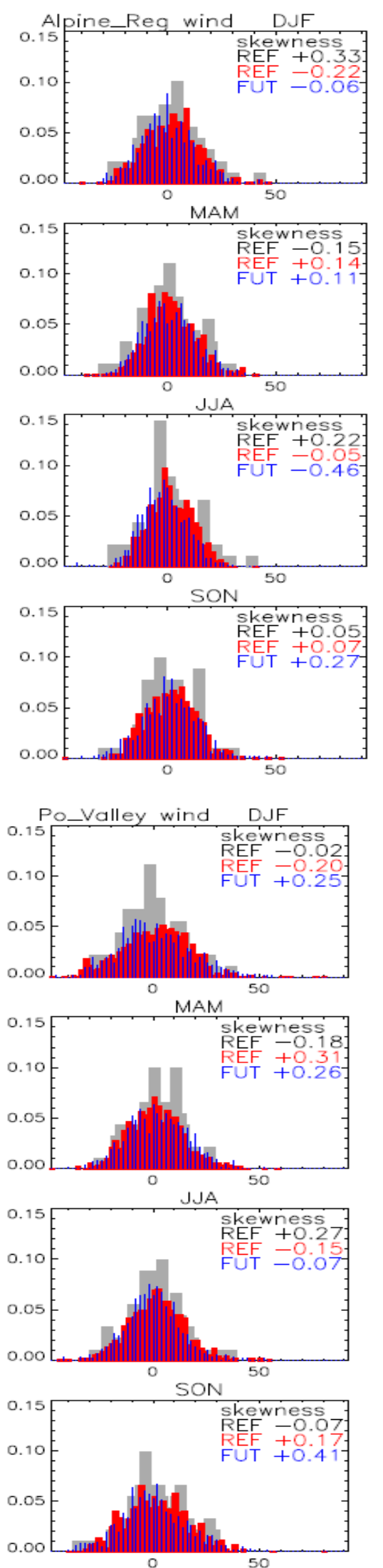

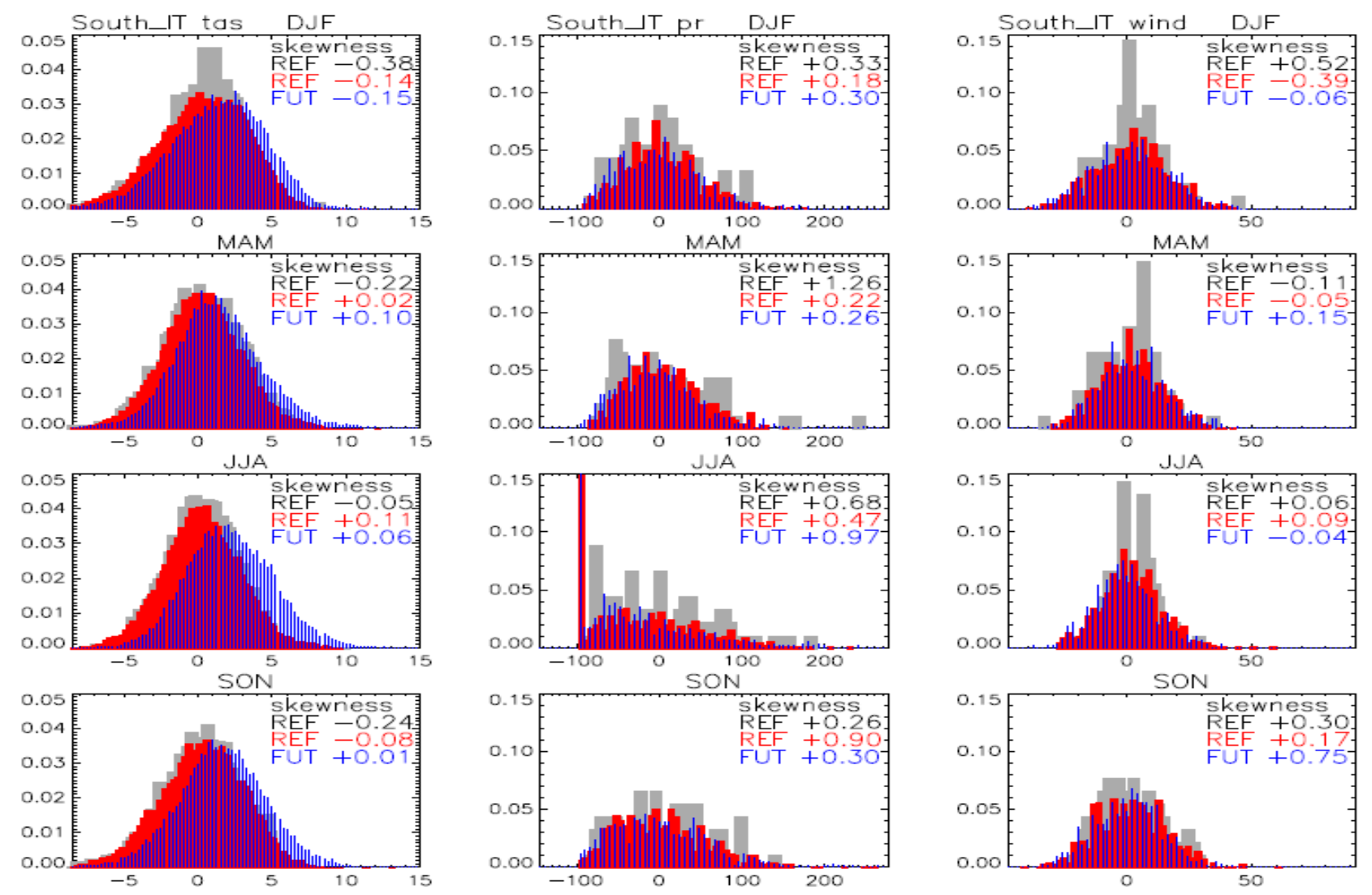

(c)

Fig. 13 (a) Normalized anomalies distribution for tas (daily values $\left({ }^{\circ} \mathrm{C}\right.$ ), left column), $p r$ (monthly values $(\%)$, center column) and wind (monthly values (\%), right column), over Alpine region, from the top to the bottom, grey histograms represent PDF of EOBS in DJF, MAM, JJA and SON relative to REF period, analogously, red and blue histograms depict PDFs of MED in REF and FUT times, (b) as in the Fig. 13(a) but for Po valley and (c) as in the Fig. 13(a) but for southern Italy.

MAM, JJA and SON) for ALP (a), POV (b) and SIT (c) sub-regions. EOBS PDF anomalies in REF period are depicted with gray histograms.

The MED PDFs anomalies in REF and FUT periods are represented with red and blue histograms respectively. Moreover, skewness indexes are reported to characterize the symmetry of the distribution.

These PDFs, generally symmetric and shaped similar to a "Gaussian" curve, let infer some simple statistical results: it is evident a good superimpositions of EOBS and MED PDFs in the REF period, even if there is a general widening and flattering of the distribution for MED anomalies, because of the spread of the models.

Concerning tas, the comparison of FUT and REF PDFs indicates a substantial shift toward higher temperatures and a general widening and flattering of the distribution for each sub-region. Moreover, the distribution becomes slightly asymmetric especially in the summer season (JJA) with a longer hot season tail, meaning a relative increase of extreme warm events and highlighting a future scenario with an increased occurrence of very hot summers.

About $p r$, it is detectable an increase in the frequency of low-precipitation, above all in the summer season over SIT area, with a consequent increasing risk for droughts, whereas, in the others two sub-regions, the PDFs do not change substantially.

Regarding wind, no substantial change is projected in any sub-region.

\section{Conclusions}

There is a great interest for the climatic changes projected over the Mediterranean basin, having a quite 
unique character and being identified as a very vulnerable area.

On the basis of ten transient ENSEMBLES simulations, a multi-model ensemble (ENS) has been calculated by adopting the criteria to consider the seven best performing models, selected by using BIAS index as metric, to produce probabilistic projections.

Although some uncertainties, ENS fields represent the observed seasonal patterns satisfactorily both in amplitude and phase. ENS results are closer to observation values than individual model estimates, but they are affected again by some discrepancies against reference data, with a slight tendency to underestimate temperature and overestimate precipitation and wind over mountain regions, even if these biases might be attributed to some shortcomings in the reference data-sets.

Some robust findings about the climatic changes for the first half of the 21 st century have been achieved concerning Mediterranean region centre over Italy.

The scenarios presented here dealing with incremental changes of temperature, precipitation and wind speed, as well as changes of severe weather events. In this last case, seasonal 10th and 90th percentile fields for temperature and precipitation have been analyzed and a probabilistic approach has been implemented to characterize vulnerable areas to heavy precipitations, windy days, storms and wet-snow events.

The most significant results confirm the Alpine region and the whole Mediterranean basin are very sensitive to climate changes, with significant changes in temperature extremes consistent with warming and precipitation changes much more spatially heterogeneous compared with temperature changes.

Focusing over Italy, the main conclusions can be summarized in the following points:

There is a general warming over the whole Peninsula (an overall substantial temperature changes of 1-1.5 ${ }^{\circ} \mathrm{C}$ ), with the largest temperature increase expected to take place in summer (with a mean increase of 2-2.5 ${ }^{\circ} \mathrm{C}$ ), facilitating a substantial increase of extremely hot days especially in Southern Italy. It is worth noting the signal of increasing temperature in winter: the projected warming of $1.5-2{ }^{\circ} \mathrm{C}$ over Alpine region represents a serious risk for snow cover reduction and an hazard for substantial Alpine glacier melting and trigger the conditions for wet-snow events, expected to increase of about $30 \%-40 \%$ by 2050 ;

The number of dry days is expected to increase, above all during summer in southern Italy, indicating an increasing risk for droughts, one of the most damaging natural hazards affecting the southern Europe, causing detrimental impacts on agriculture, water resources and ecosystems;

Wet and very wet days are projected to change depending on the season and the location. This can imply that when it rains it will rain more intensely and strongly, especially at certain locations: the central-north areas in winter, the eastern coastal sites in spring and most of the Italian peninsular regions during autumn will be interested by an increase of at least of $10 \%$ of heavy rainy days;

If the projected increased of high pressure and anticyclonic conditions over Mediterranean basin generally lead to a greater stability and consequently to conditions less favorable to wind regimes, some areas will be likely interested by an increase of storm events: Tyrrhenian coasts in the winter season and Adriatic coastal areas and Ionic regions in spring.

\section{Acknowledgements}

This work has been financed by the Research Fund for the Italian Electrical System under the Contract Agreement between RSE (formerly known as ERSE) and the Ministry of Economic Development - General Directorate for Nuclear Energy, Renewable Energy and Energy Efficiency stipulated on July 29, 2009 in compliance with the Decree of March 19, 2009.

The E-OBS and ENSEMBLES data used in this work was funded by the EU FP6 Integrated Project ENSEMBLES whose support is gratefully 
acknowledged.

ECMWF ERA-INTERIM data have been provided by ECMWF data server.

The author is very grateful to the Dario Ronzio (Ph.D. Researcher at RSE) for his help in decoding climate archives, through which the climate analysis for the Mediterranean region was made possible, and for his constructive comments. Moreover, the author thanks Anna Toppetti (Researcher at RSE) for her very useful contribution in the statistical data analysis and Andrea Amicarelli (Ph.D. researcher at RSE) for valuable discussions.

\section{References}

[1] European Environmental Agency. 2012. Climate Change, Impacts and Vulnerability in Europe 2012. An Indicator-Based report.

[2] Giorgi, F. 2006. "Climate Change Hot-Spots." Geophys. Res. Lett. 33: L08707.

[3] Giorgi, F., and Lionello, P. 2008. "Climate Change Projections for the Mediterranean Region." Global and Planetary Change 63: 90-104.

[4] Faggian, P., and Giorgi, F. 2009. "An Analysis of Global Model Projections over Italy, with Particular Attention to the Italian Greater Alpine Region (GAR)." Climatic Change 96: 239-258.

[5] Christensen, J. H., Carter, T. R., Rummu, Kainen, M., and Amanatidis, G. 2007. "Evaluating the Performance and Utility of Regional Climate Models: The PRUDENCE." Climatic Change 81: 1-6.

[6] Gualdi, S. 2013. "The CIRCE Simulations, Regional Climate Change Projections with Realistic Representation of the Mediterranean Sea." American Met. Soc. 94 (1): 65-81.

[7] Van Der Linden, P., and Mitchell, J. 2009. ENSEMBLES: Climate Change and Its Impacts: Summary of Research and Results from the ENSEMBLES Project. Exeter: Met Office Hadley Centre.

[8] Giorgi, F., Jones, C., and Asrar G. R. 2009. "Addressing Climate Information Needs at the Regional Level: The CORDEX Framework." WMO Bulletin 58 (3) 175-183.

[9] Deque, M., Rowell, D. P., Luthi, D., Giorgi, F., Christensen, J. H., and Rockel, B. 2007. "An Intercomparison of Regional Climate Simulations for Europe: Assessing Uncertainties in Model Projections." Climatic Change 81: 53-70. doi:10.1007/s10584-006-9228-x.

[10] Gibelin, A. L., and Deque, M. 2003. "Anthropogenic Climate Change over the Mediterranean Region
Simulated by a Global Variable Resolution Model." Climate Dyn. 20: 327-339.

[11] Gao, X., Pal, J. S., and Giorgi, F. 2006. "Projected Changes in Mean and Extreme Precipitation over the Mediterranean Region from a High Resolution Double Nested RCM Simulation.” Geophysycal Research Letters 33: L03706. doi:10.1029/2005GL024954.

[12] Turco, M., Sanna, A., Herrera, S., Llasat, M. C., and Gutierrez, J. M. 2013. "Large Biases and Inconsistent Climate Change Signals in ENSEMBLES Regional Projections." Climatic Change 120: 859-869.

[13] Prein, A. F., Gobietm, A., and Truhetz, H. 2011. "Analysis of Uncertainty in Large Scale Climate Change Projections over Europe." Meteorologische Zeitschrift 20 (4): 383-395.

[14] Haylock, M. R., Hofstra, N., Klein Tank AMG, Klok, E. J., Jones, P. D., and New, N. 2008. “A European Daily High-Resolution Gridded Dataset of Surface Temperature and Precipitation." J. Geophys. Res (Atmospheres) 113: D20119. doi:10.1029/2008JD10201.

[15] Simmons, A. J., and Hollingsworth, A. 2002. "Some Aspects of the Improvement of Skill of Numerical Weather Prediction." Quart. J. Roy. Meteor. Soc. 128: 647-677.

[16] Nakicenovic, N. 2000. Special Report on Emissions Scenarios: A Special Report of Working Group III in the Intergovernmental Panel on Climate Change. England: Cambridge University Press.

[17] Rockel, B., and Woth, K. 2007. "Extremes of Near-Surface Wind Speed over Europe and Their Future Changes as Estimated from an Ensemble of RCM Simulations." Climatic Change 81 (1): 267-280.

[18] Kjellstrom, E., Boberg, F., Castro, M., Christensen, J. H., Nikulin, G., and Sanchez, E. 2010. "Daily and Monthly Temperature and Precipitation Statistics as Performance Indicators for Regional Climate Models." Climate Research 44: 135-150.

[19] Frei, C., and Schar, C., 1998. "A Precipitation Climatology of the Alps from High-Resolution Rain-Gauge Observations.” Int. J. Climatol 18: 873-900.

[20] Glecker, P. J., Taylor, K. E., and Doutriaux, C. 2008. "Performance Metrics for Climate Models." J. Geophys. Res. 113: D06104. doi:10.1029/2007JD008972.

[21] Coppola, E., Giorgi, F., Rauscher, S. A., and Piani, P. 2010. "Model Weighting Based on Mesoscale Structures Inprecipitation and Temperature in an Ensemble of Regional Climate Models." Clim. Res. 44: 121-134. doi:10.3354/cr00940.

[22] Kjellstrom, E., Boberg, F., Castro, M., Christensen, J. H., Nikulin, G., and Sanchez, E. 2010. "Daily and Monthly Temperature and Precipitation Statistics as Performance Indicators for Regional Climate Models.” Climate 
Research 44: 135-150.

[23] Adam, J. C., and Lettenmaier, D. P. 2003. "Adjustment of Global Gridded Precipitation for Systematic Bias." Journal of Geophysical Research 108 (D9): 4257. doi:10.1029/2002JD002499.

[24] Hofstra, N., Haylock, M., New, M., and Jones, P. D. 2009. "Testing E-OBS European High-Resolution Gridded Data Set of Daily Precipitation and Surface Temperature." Journal of Geophysical Research 114: D21101. doi.10.102972009JD11799.

[25] Christensen, J. H., Carter, T. R., Rummukainen, M., and Amanatidis, G. 2007. "Evaluating the Performance and Utility of Regional Models: The PRUDENCE Project." Clim. Change 81: 1-6. doi:10.1007/s10584-006-9211-6.

[26] Meehl, G. A. 2005. "Overview of the Coupled Model Intercomparison Project.” Bull. Am. Meteorol. Soc. 86: 89-93.

[27] Prein, A. F., Gobietm, A., and Truhetz, H. 2011. "Analysis of Uncertainty in Large Scale Climate Change Projections over Europe." Meteorologische Zeitschrift 20 (4): 383-395.

[28] Zampieri, M., Giorgi, F., Lionello, P., and Nikulin, G. 2012. "Regional Climate Change in the Northern Adriatic." Physics and Chemistry of the Earth 40-41: 32-46. doi:10.1016/j.pce.2010.02.003.

[29] Brunetti, M., Lentini, G., Maugeri, M., Nanni, T., Simolo, C., and Spinoni, J. 2012. "Projecting North Eastern Italy Temperature and Precipitation Secular Records onto a High Resolution Grid." Physics and Chemistry of the Earth 40-41: 9-22.

[30] Coppola, E., and Giorgi, F. 2010. "An Assessment of Temperature and Precipitation Change Projections over Italy from Recent Global and Regional Climate Model Simulation.” Inter. J. of Climatology 30: 11-32.

[31] Rockel, B., and Woth, K. 2007. "Extremes of Near-Surface Wind Speed over Europe and Their Future Changes as Estimated from an Ensemble of RCM
Simulations.” Climatic Change 81 (1): 267-280.

[32] Scocciamarro, E., Gualdi, S., Bellucci, A., Zampieri, M., and Navarra, A. 2013. "Heavy Precipitation Events in a Warmer Climate: Results from CMIP5 Models.” Journal of Climate 26: 7902-7911. doi:10.1175/JCLI-D-12-00850.1.

[33] Fischer, E. M., and Knutti, R. 2014. "Detection of Spatially Aggregated Changes in Temperature and Precipitation Extremes." Geophysical Research Letters 41: 1-8. doi:10.1002/2013GL058499

[34] Nikulin, G., Kjellsrom, E., Hasspn, U., Strandberg, G., and Ullerstig, A. 2011. "Evaluation and Future Projections of Temperature, Precipitation and Wind Extremes over Europe in an Ensemble of Regional Climate Simulations." Tellus 63 (A): 41-55.

[35] Beniston, M., Stephenson, D. B., Christiansen, O. B., Ferro, C. A. T., Frei, C., and Goyette, S. et al. 2007. "Future Extreme Events in European Climate: An Exploration of Regional Climate Model Projections." Climatic Change 81: 71-95.

[36] Kiktev, D., Sexton, D., Alexander, L., and Folland, C. 2003. "Comparison of Modelled and Observed Trends in Indicators of Daily Climate Extremes." Journal of Climate 16 (22): 3560-71.

[37] Alexander, L. V. 2006. "Global Observed Changes in Daily Climate Extremes of Temperature and Precipitation." J. Geophys. Res. 111: D05109. doi:10.1029/2005JD006290.

[38] Donat, M. G. 2013. "Updated Analyses of Temperature and Precipitation Extreme Indices since the Beginning of the Twentieth Century: The HadEX2 Dataset." J. of Geophysical Research: Atmosphere 118: 2098-2118. doi:10.1002/jgrd.50150.

[39] Mastrandrea, M. D. 2010. "Guidance Notes for Lead Authors of the IPCC Fifth Assessment Report on Consistent Treatment of Uncertainties." Accessed October 7, 2013. http://www.ipcc.ch. 